\title{
GRANDPARENTS AND GREAT-GRANDPARENTS IN ESTONIAN POPULATION
}

\author{
ENe-Margit TitT \\ Institute of Mathematics and Statistics, University of Tartu, Tartu, Estonia
}

\begin{abstract}
The paper estimates the probability of living until the age of a grandparent and a great-grandparent in different cohorts of Estonian population. The objects of comparison are men and women born in 1939, 1959, 1989 and nowadays (2016). It turned out that (assuming the stability of demographic behaviour) people born in 1989 have the highest probability to see the grandchildren and also great-grandchildren. In the case of people born in 21 st century, the probability is going down in spite of increasing life expectancy. The reason for this feature is massive postponing of family creation.
\end{abstract}

Keywords: life expectancy; probability of having grandchildren; birth cohort

\section{INTRODUCTION}

During the last century, the age structure of Estonian population has changed drastically. Changes are also quite large between different generations. Similar changes have appeared in other Western communities, too.

In the paper, the population statistics of four time moments are regarded: years 1929, 1959, 1989 and today, that is 2017 (statistics of the current year are not available). For the years chosen, a full set of population data, including death ages, exists in the open database of Statistics Estonia (www.stat.ee).

The life expectancy has considerably increased during the period, but the age of marriage and average age of giving birth have changed, too, although no one-way trend exists - the period of decreasing age of family-making has changed to a period of postponing important decisions. 
It is well-known that the share of elderly persons in the population increases. We ask - does this also mean that the share of grandparents and great-grandparents increases? And from here follows the question - which impact do the changes in the structure of the population have on the mentality of the population? Are these changes accompanied by changes in the role structure of households and other social groups?

\section{Methodology}

As usual in population statistics, we assume that, looking people at some fixed time moment, they have the same behaviour in the sense of population statistics.

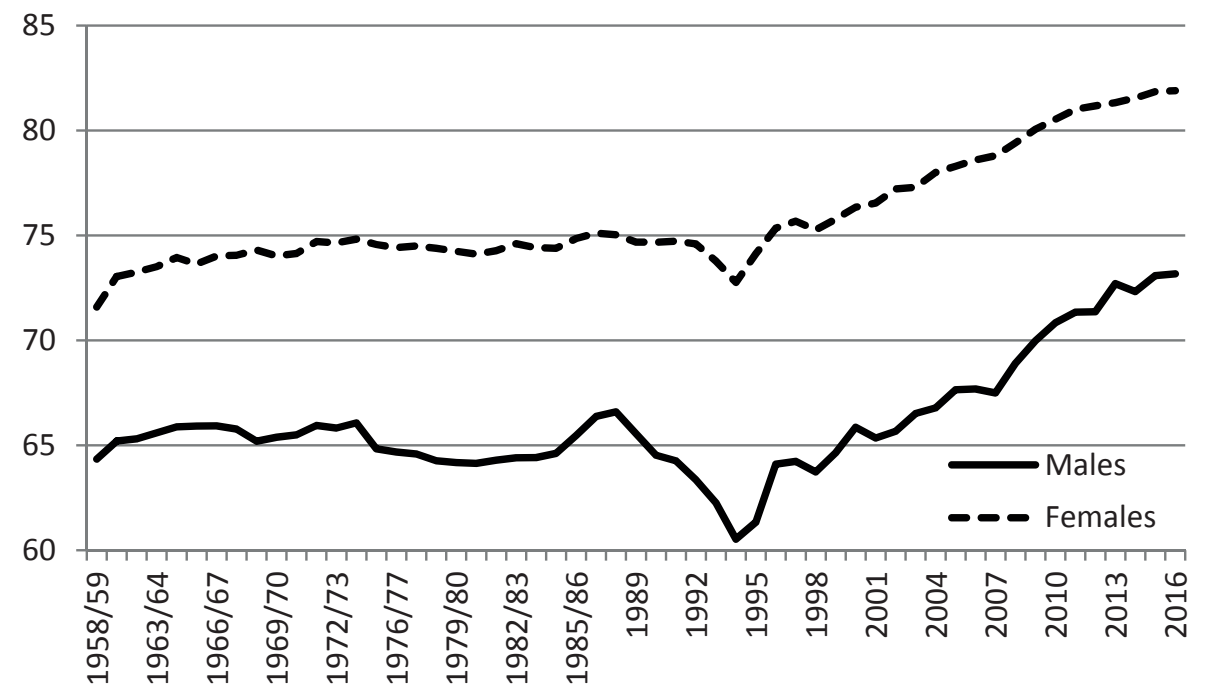

Figure 1. The changes in life expectancy in time.

In calculations, we use the estimated life expectation for different generations (see Figure 1), especially the number of survivors for different ages of different generations (see Figure 2). Additionally, we use the mean age of giving birth of women (see Figure 3 ) and the time of starting family life or getting a child for men (that was measured for some generations, and we had to assess it for the earlier generation). 


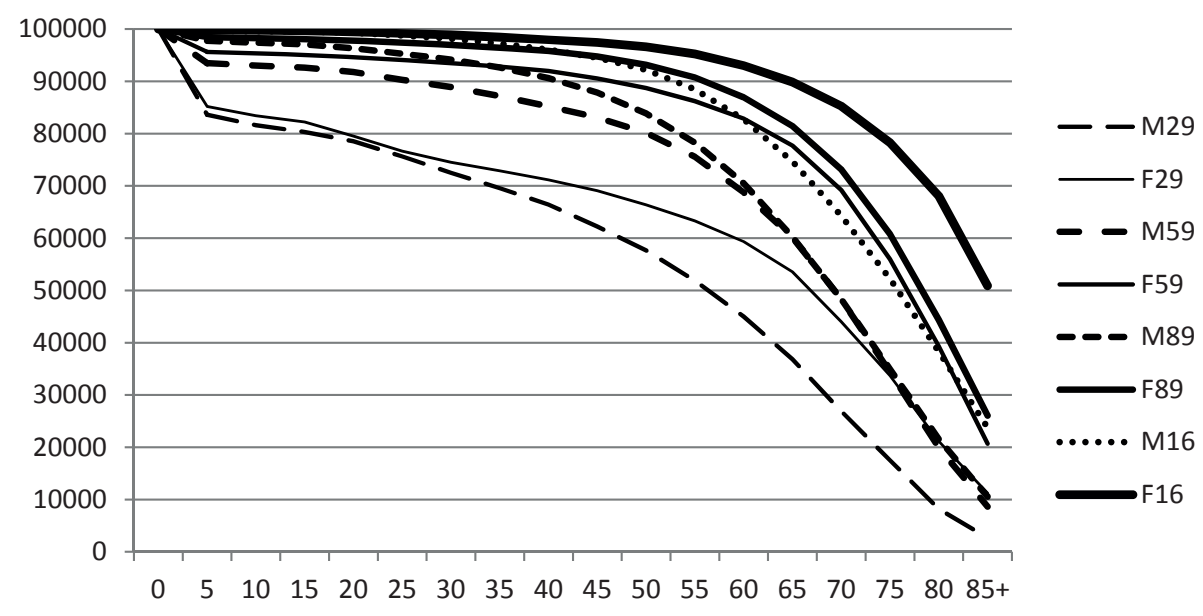

Figure 2. The share of survivors (men and women) in different generations. Here M29 means the males born in 1929 and F16 the females born in 2016 (supposed that the death rate remains on the level of this year)

From Figure 2, we can make the following conclusions: (1) from boys and girls born in 1929 , about $80-85 \%$ had the chance to celebrate their 5th birthday; (2) in all generations, there exists a remarkable difference between the survivors among men and women; (3) the behaviour of women and especially of men born in 1959 and 1989 is quite similar; (4) the number of survivors has continuously risen in time.



Figure 3. The mean age of giving birth for women of different generations 
In our calculations, we also use the fact that about 10 percent of women of different generations in Estonia have been childless. The childlessness of men has never been statistically measured, but we suppose that the same number is true for men. The age of giving birth has been modelled using normal distribution - in fact, this causes some bias, but not very big, as seen in Figure 3.

All the results are estimated probabilities, not statistically measured data.

\section{The men born in 1929}

This generation was strongly endangered by infectious diseases, so about $20 \%$ of boys born died as babies or in childhood. The average age of men for marrying and creating a family was about 30 years, and $70 \%$ of men lived up to this time. Nevertheless, some young men started family life earlier, being only 20 years old. The "best" age for married men was 45 , then the share of married men from all born in 1929 was the biggest, but it did not reach 50\% from the birth cohort. At the same age, several men reached the status of grandfather, but the number of grandfathers increased rather slowly. At all, only one of six boys of this birth cohort saw their grandchildren. Most probably, this happened at the age of 65 .

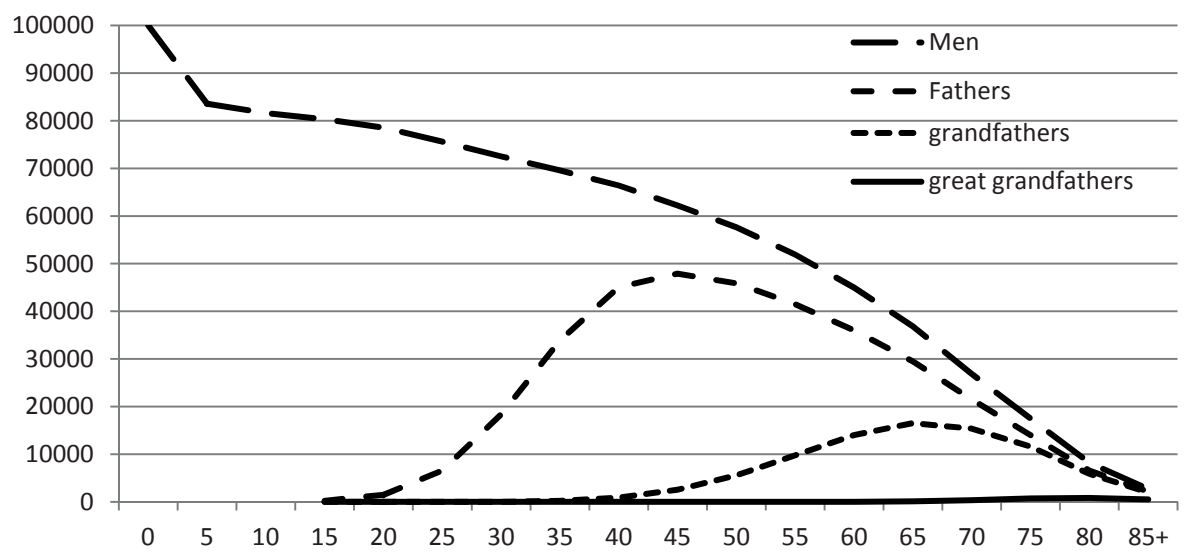

Figure 4. Fathers, grandfathers and great grandfathers in the 1929 generation 


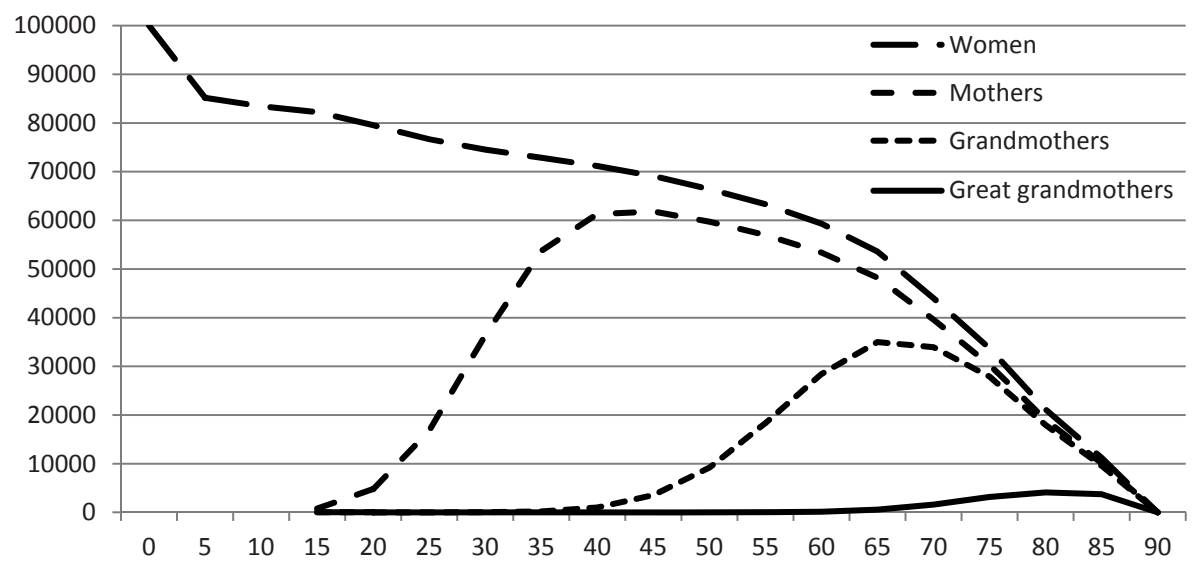

Figure 5. Mothers, grandmothers and great-grandmothers in the generation born in 1929.

The share of men who had great-grandchildren during their lifespan was almost $1 \%$ of the birth cohort.

\section{The women born in 1929}

At that time the women's destiny in childhood was quite similar to that of men. Only $85 \%$ of girls born in 1929 saw their 5th birthday. But the share of women who lived up to the age of motherhood was more than $60 \%$, and the age when the share of mothers among women reached the maximum was 40 years. This means that the death rate of women in breeding age was quite low. About 35\% of the birth cohort also reached the status of the grandmother. This happened in quite a wide window of age, starting in the 40s and reaching the maximum in 65. About five percent of women from this cohort also had great-grandchildren; in most cases, this happened when they were $70-85$ years old - if they survived to this age.

\section{The men born in 1959}

During the period of 1929-1959, the infants' and children's death rate had fallen, and the share of boys surviving up to their 5th birthday was about $92 \%$. The reason was more effective forestalling and therapy of children's infectious diseases. So, almost $3 / 4$ of boys from the birth cohort reached the age of fatherhood, starting from 15-20 years and gaining the maximum value at the age of $40-50$. At the age of 40, some men also had grandchildren, and, in total, $40 \%$ of men from the birth cohort can get the status of a grandfather. Also, to be a great-grandfather is possible for $5 \%$ of men from this birth cohort. 


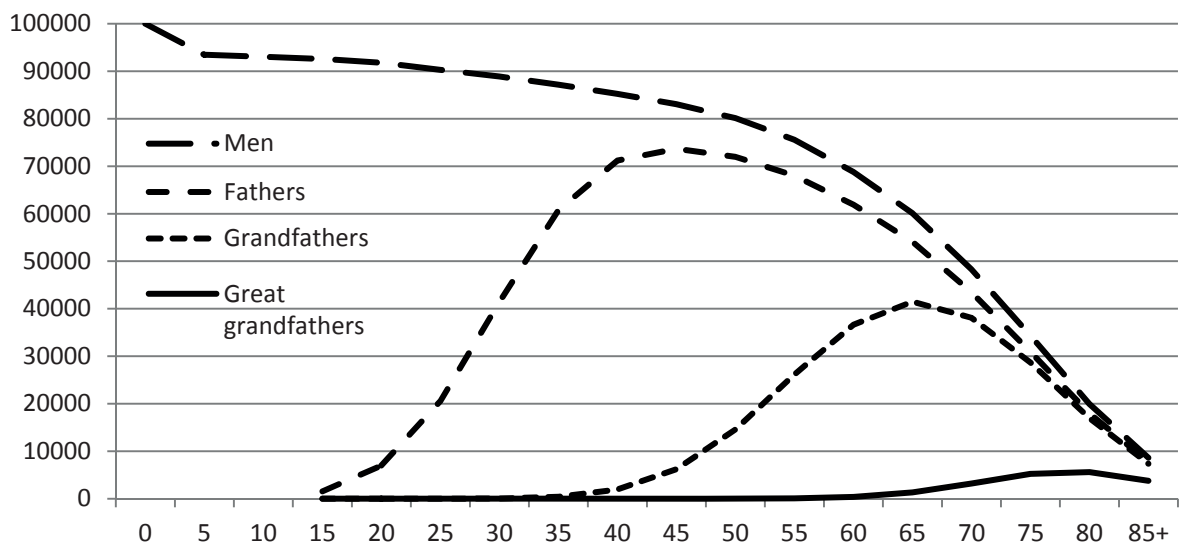

Figure 6. Fathers, grandfathers and great-grandfathers in the 1959 generation

\section{The women born in 1959}

From girls born in 1959, about 95\% went through the most dangerous first five years and survived up to the fertile age. Many of them started motherhood rather early - already before the 20th birthday almost one of ten women had a child, and at the age of 35 , more than $80 \%$ of women were mothers. Similarly, the grandmotherhood of this generation started quite early, and $60 \%$ of women of this cohort have grandchildren. In a similar way, almost $15 \%$ of them can have great-grandchildren at the age of 80 .

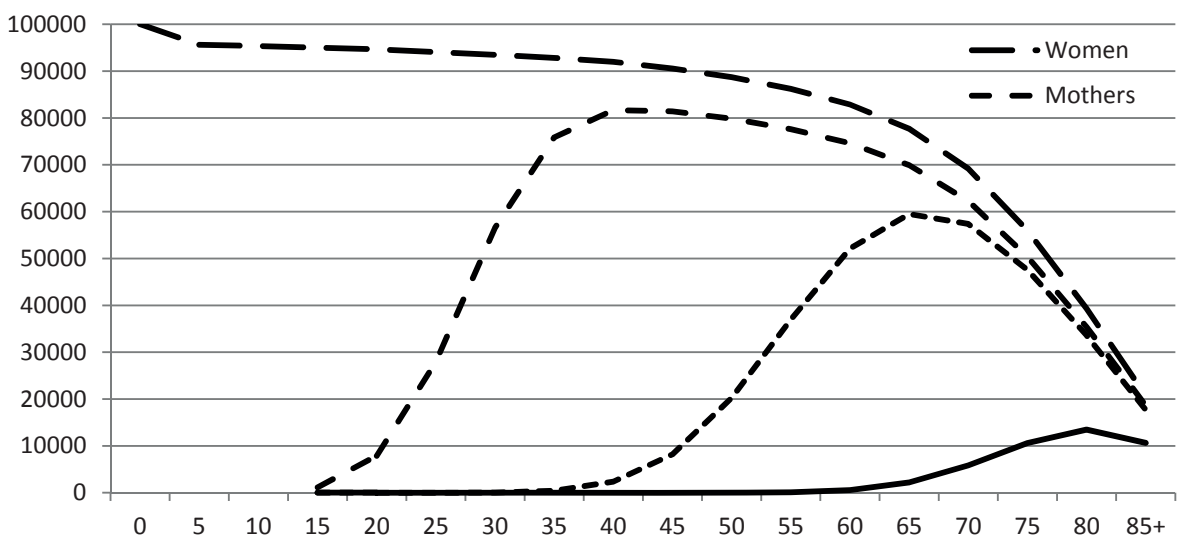

Figure 7. Mothers, grandmothers and great grandmothers in the 1959 generation 


\section{The men born in 1989}

The probability to survive until the school-age has increased for boys born in 1989 and also the risk to die during the school-years has dropped. Still, about $10 \%$ of men do not see their late thirties. The starting point of family life is quite early; a number of men are fathers in teenager years and in the early twenties, and the share of men being fathers is quite high $-80 \%$ for men aged 35-40 years. But from this point onwards, the share of survivors decreases rather rapidly, and the share of men having grandchildren remains less than $50 \% .10 \%$ of all men from this cohort can have great-grandchildren.

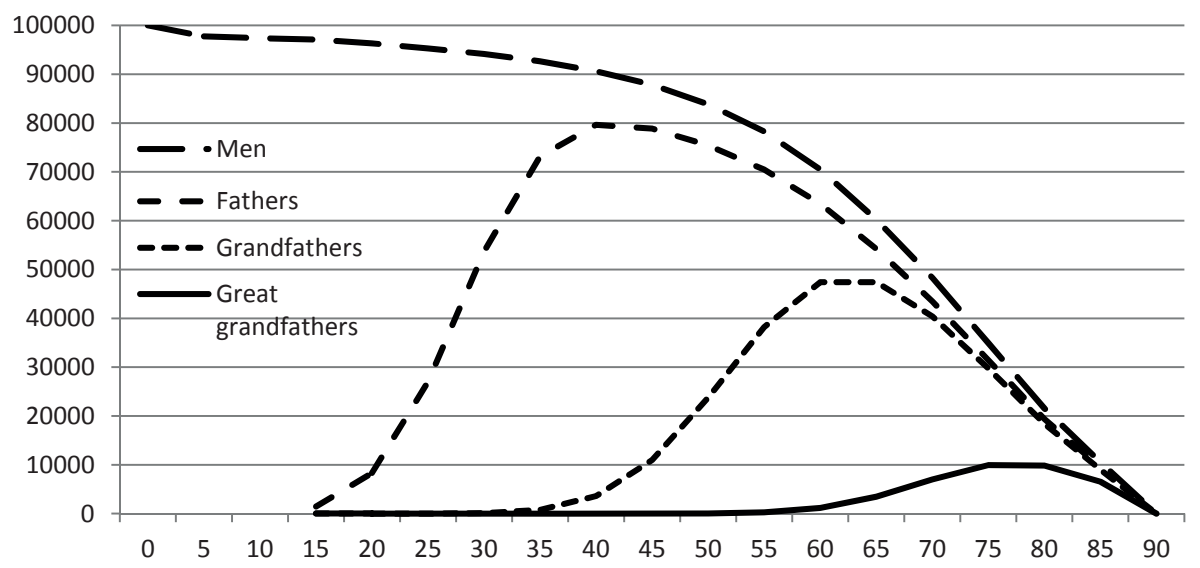

Figure 8. Fathers, grandfathers and great-grandfathers in the 1989 generation.

\section{The women born in 1989}

The girls born in 1989 had few reasons for being afraid of childhood infections, as only two girls from one hundred of the cohort died before their 15th birthday. The women of this cohort started their family life very early, and, already by the age of 25, about half of them were mothers. The share of mothers increased rapidly and reached more than $85 \%$ of the cohort. Some women of the cohort got their first grandchildren before the 40th birthday, and, by the 65th birthday, $65 \%$ of the cohort had already grandchildren. This cohort is also quite active in having great-grandchildren - about $1 / 4$ of them will have the chance to celebrate their 80th birthday having one or more great-grandchildren. 


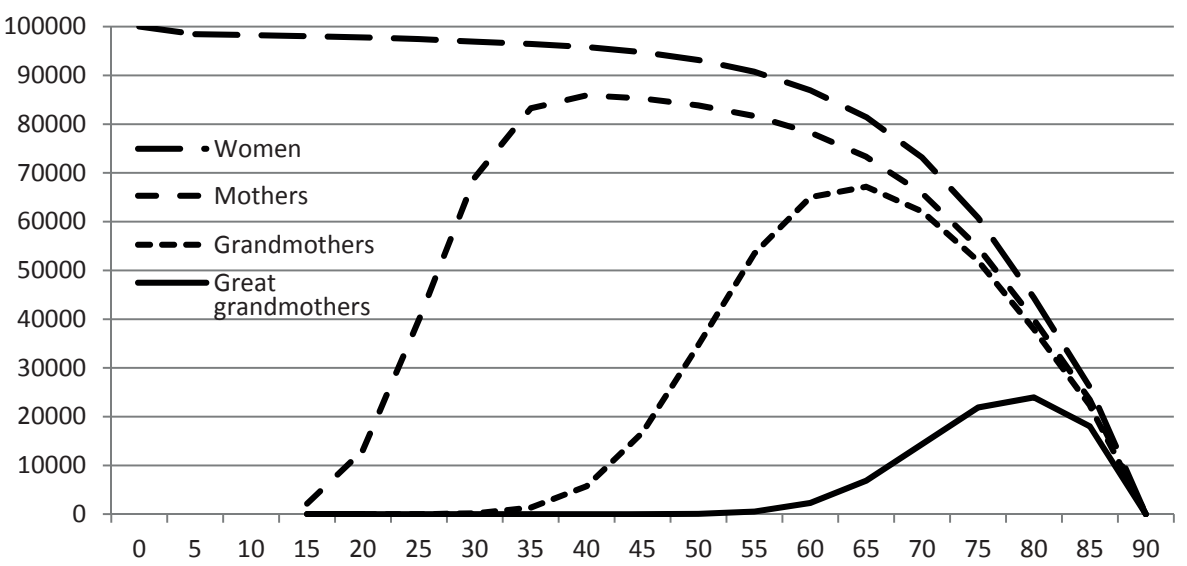

Figure 9. Mothers, grandmothers and great-grandmothers of the 1989 generation

\section{The men born in 2016}

More than $99 \%$ of boys born in 2016 survive their childhood and reach adulthood. But unlike the earlier generations, they do not hurry with starting the family life and having children. On the 25th birthday, only less than $10 \%$ of men have children - that is twice less than the cohort of their fathers had. But due to longer expected life, more than $80 \%$ of the cohort reach the age of having children. Still, it is not guaranteed that all of them will have children. Because of late start of family life, only about $40 \%$ of the generation will have grandchildren and quite few - about $5 \%$ - will have great-grandchildren.

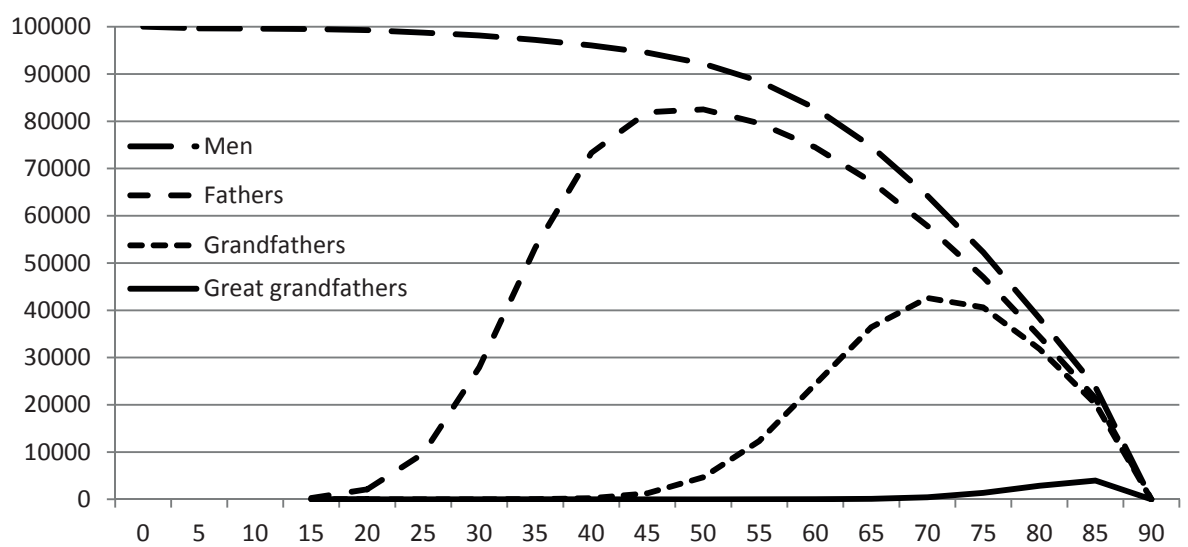

Figure 10. Fathers, grandfathers and great-grandfathers in the 2016 generation. 


\section{The women born in 2016}

The girls from the birth cohort typical of today do not have to fear childhood diseases, and almost $100 \%$ of them survive up to the fertile age. But similarly to men of the cohort, the young women do not hurry with giving birth. More than $85 \%$ of them live so long that they might have children, but, in general, it happens in most cases in the thirties, and so the maximum number of (living) mothers from this cohort is about $35-45$ years old. Still quite a big number of them will also have grandchildren at the age of about 70 , but the number of great-grandmothers will be lower than in the generation of their mothers.

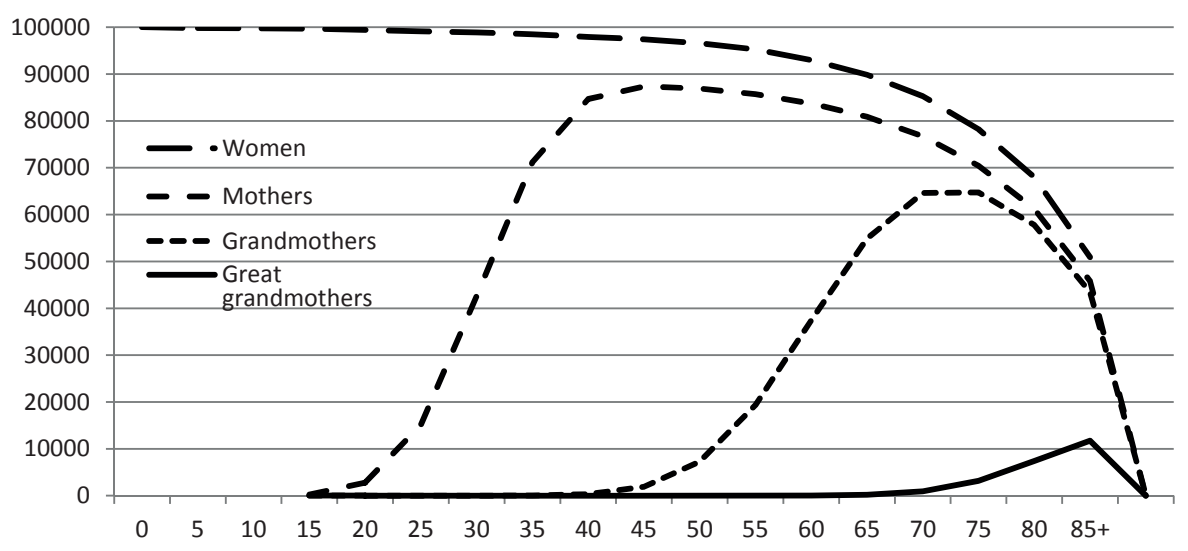

Figure 11. Mothers, grandmothers and great-grandmothers in the 2016 generation.

\section{CONCLUSION}

The changes in demographic behaviour give also rise to several changes in society. In general, it is a well-known fact that nowadays the population is growing older; the share of elderly people increases in almost all developed countries. It is also known that today people start their family life later than it happened earlier. Both these changes have their impact on the generations' structure in the sense of parents, grandparents and great-grandparents.

Figure 12 demonstrates that during the last century the probability of men and women to live until the birth of grandchildren and great-grandchildren increased steadily, but, in the 21st century, the probability of being a grandparent almost stabilised, but the probability of having great-grandchildren dropped because of postponing the start of family life. 


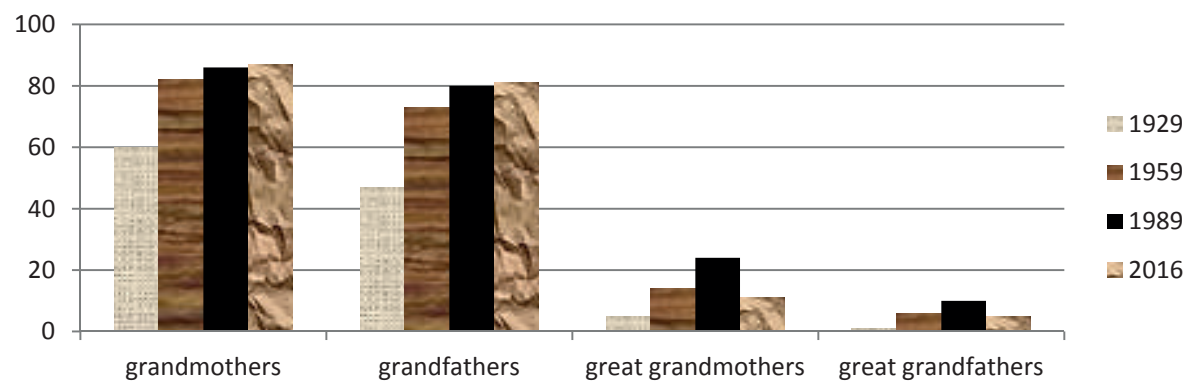

Figure 12. Estimated probability of reaching the status of grandparents and great-grandparents for men and women of different birth cohorts.

\section{Address for correspondence:}

Ene-Margit Tiit

Institute of Mathematics and Statistics

University of Tartu, Tartu, Estonia

J. Liivi 2-509, 50409 Tartu, Estonia

E-mail: ene.tiit@ut.ee 